\title{
Interaction between the genomes of Lactococcus lactis and phages of the P335 species
}

\author{
William J. Kelly*, Eric Altermann, Suzanne C. Lambie and Sinead C. Leahy
}

AgResearch Limited, Grasslands Research Centre, Palmerston North, New Zealand

\section{Edited by:}

Andrea Del Luján Quiberoni, Consejo Nacional de Investigaciones

Científicas y Técnicas - Universidad

Nacional del Litoral, Argentina

\section{Reviewed by:}

Mariángeles B. Marcó, Instituto de

Lactología Industrial, Argentina

Diego J. Mercanti, Instituto de

Lactología Industrial IUniversidad

Nacional del Litoral - Consejo

Nacional de Investigaciones

Científicas y Técnicas), Argentina

*Correspondence:

William J. Kelly, AgResearch

Limited, Grasslands Research

Centre, Tennent Drive, Private Bag

11008, Palmerston North 4442,

New Zealand

e-mail:bill.kelly@agresearch.co.nz
Phages of the P335 species infect Lactococcus lactis and have been particularly studied because of their association with strains of L. lactis subsp. cremoris used as dairy starter cultures. Unlike other lactococcal phages, those of the P335 species may have a temperate or lytic lifestyle, and are believed to originate from the starter cultures themselves. We have sequenced the genome of L. lactis subsp. cremoris KW2 isolated from fermented corn and found that it contains an integrated P335 species prophage. This $41 \mathrm{~kb}$ prophage $(\Phi \mathrm{KW} 2)$ has a mosaic structure with functional modules that are highly similar to several other phages of the P335 species associated with dairy starter cultures. Comparison of the genomes of 26 phages of the P335 species, with either a lytic or temperate lifestyle, shows that they can be divided into three groups and that the morphogenesis gene region is the most conserved. Analysis of these phage genomes in conjunction with the genomes of several $L$. lactis strains shows that prophage insertion is site specific and occurs at seven different chromosomal locations. Exactly how induced or lytic phages of the P335 species interact with carbohydrate cell surface receptors in the host cell envelope remains to be determined. Genes for the biosynthesis of a variable cell surface polysaccharide and for lipoteichoic acids (LTAs) are found in L. lactis and are the main candidates for phage receptors, as the genes for other cell surface carbohydrates have been lost from dairy starter strains. Overall, phages of the P335 species appear to have had only a minor role in the adaptation of L. lactis subsp. cremoris strains to the dairy environment, and instead they appear to be an integral part of the L. lactis chromosome. There remains a great deal to be discovered about their role, and their contribution to the evolution of the bacterial genome.

Keywords: phage, Lactococcus lactis subsp. cremoris, dairy, starter culture, genome, integrase, cell wall polysaccharides

\section{INTRODUCTION}

The role of Lactococcus lactis as the key organism in the initiation of milk fermentation has been known since the work of Joseph Lister in the 1870s when Bacterium lactis was the first bacterium to be isolated in pure culture (Santer, 2010). Today this species is the main constituent of cultures used for the manufacture of a vast range of fermented dairy products, including fermented milks, sour cream, soft and hard cheeses, and lactic casein. The taxonomy of $L$. lactis is confused by discrepancies between phenotypic and genotypic descriptions but it is apparent that two subspecies exist that correlate with genotype and are known as L. lactis subsp. cremoris and L. lactis subsp. lactis (Kelly et al., 2010). Both subspecies are used as starters by the dairy industry but the strains with the L. lactis subsp. cremoris genotype cluster closely together (Rademaker et al., 2007), and are particularly favored for use as defined strain starter cultures for Cheddar cheese production.

The use of defined strain starters began in New Zealand in the 1930s using bacteria selected from mixed strain cultures, and studies of bacteriophages that infect dairy cultures began around the same time (Whitehead and Cox, 1936), as fermentations using single strain starters quickly proved to be susceptible to phage attack. Subsequently, phage resistance and the selection and characterization of phage-unrelated strains, became the major focus of dairy starter culture research (Lawrence et al., 1978), and it was concluded that a relatively small number of significantly different $L$. lactis subsp. cremoris starter strains exist (Whitehead and Bush, 1957; Lawrence et al., 1978; Kelly et al., 2010). Initial studies investigated whether phages originated from the dairy environment or from the cultures themselves, but eventually the environmental origin came to be regarded as the most significant and a range of measures were developed to control phage attack (Whitehead, 1953). Nevertheless, phage attack, leading to slow or dead vats, remains the leading cause of fermentation problems in the dairy industry. It was also discovered that most starter strains were lysogenized by one or more bacteriophage, and that these temperate phages could be induced, although it was difficult to find strains that they could be propagated on (Huggins and Sandine, 1977; Terzaghi and Sandine, 1981).

Bacteriophages from $L$. lactis were originally divided into 12 species within the Siphoviridae and Podoviridae based on morphology and DNA homology, and type phages were selected to represent each species (Jarvis et al., 1991). Subsequent studies have refined the number of species to 10 (Deveau et al., 2006), with most of the phage problems encountered in dairy 
fermentations ascribed to just three species. These are the small isometric-headed 936 and P335 species, and the prolateheaded c2 species. The 936 and c2 species are lytic whereas phages from the P335 species may have a temperate or lytic lifestyle (Braun et al., 1989). Phages of all three species have now had their genomes sequenced and while phages from the 936 and c2 species form distinct but homogeneous groups, the phages from the P335 species are much more heterogeneous and their genomes appear to be mosaic in structure similar to the lambdoid phages. Most studies of phages of the P335 species have focused on their lytic or temperate relationship with L. lactis subsp. cremoris dairy starter strains. Here we describe a prophage from the genome of a non-dairy L. lactis subsp. cremoris culture and compare its genome organization with a range of other phages of the P335 species from L. lactis.

\section{MATERIALS AND METHODS GENOME SEOUENCING}

L. lactis subsp. cremoris KW2 was originally isolated from kaanga wai (fermented corn) and was chosen for sequencing because in studies comparing multiple L. lactis cultures (Rademaker et al., 2007) it grouped with the L. lactis subsp. cremoris dairy starter cultures. Its genome sequence was determined using pyrosequencing of $3 \mathrm{~kb}$ mate paired-end sequence libraries on a 454 GS FLX platform with titanium chemistry (Macrogen, South Korea). Pyrosequencing reads were assembled using the Newbler assembler version 2.5.3 (Roche 454 Life Sciences, USA) resulting in 22 contigs across a single scaffold. Gap closure was managed using the Staden package (Staden et al., 2000), and gaps were closed using additional Sanger sequencing by standard PCR-based techniques. Proteinencoding genes were identified by Glimmer (Delcher et al., 1999) and a GAMOLA/ARTEMIS (Rutherford et al., 2000; Altermann and Klaenhammer, 2003) software suite was used to manage genome annotation. Assignment of protein function to ORFs was performed manually using results from BLASTP, and the COG (Clusters of Orthologous Groups, Tatusov et al., 2000), Pfam (Punta et al., 2012), and TIGRFAM (Haft et al., 2013) databases.

\section{Lactococcus lactis GENOMES}

Complete sequences are available for the chromosomes of eight L. lactis strains. For L. lactis subsp. cremoris these are the cheese starter cultures A76 (isolated in France, Bolotin et al., 2012), SK11 (isolated in New Zealand, Makarova et al., 2006) and UC509.9 (isolated in Ireland, Ainsworth et al., 2013), and the plasmidfree reference strain MG1363 (Wegmann et al., 2007). All of these strains originally derive from mixed strain dairy starter cultures. A feature of the three cheese starter cultures is that they harbor several plasmids which enable these strains to metabolize lactose and casein efficiently, and that their chromosomes contain a large number of transposases and pseudogenes. For L. lactis subsp. lactis there are genomes for the plasmid-free reference strain IL1403 which is of dairy origin (Bolotin et al., 2001), and three non-dairy strains, KF147 (Siezen et al., 2010), CV56 (Gao et al., 2011), and IO-1 (Kato et al., 2012).

\section{P335 PHAGE GENOMES}

Table 1 lists the phages belonging to the P335 species for which genome information is available. Three genomes are of lytic phages; P335 (Labrie et al., 2008), 4268 (Trotter et al., 2006), and ul36 (Labrie and Moineau, 2002), with partial genome sequence information also available for an additional lytic phage, $\Phi 31$ (Madsen et al., 2001). Six genomes are from temperate phages that have been induced from their host strain and propagated, usually on either a closely related strain (strain H2 for BK5-T) or a prophage-cured derivative (cured derivative of strain R1 for r1t). Publically available temperate phage genomes are: TP9011 (Brøndsted et al., 2001), Tuc2009 (NCBI Reference Sequence: NC_002703), r1t (van Sinderen et al., 2006), BK5-T (Desiere et al., 2001), ФLC3 (Blatny et al., 2004), and Фsmq86 (Labrie and Moineau, 2007). All of these phages have been studied because of their ability to lyse dairy starter strains, although most have a relatively narrow host range.

Seventeen complete prophages were identified in L. lactis genomes, and with the exception of UC509.9 (a derivative of UC509 that has been cured of the Tuc2009 prophage, Ainsworth et al., 2013), all of the sequenced L. lactis strains have at least one full-length P335 species prophage integrated into their chromosome (Table 1). The prophages from strains IL1403, MG1363, and SK11 have been described in detail previously (Chopin et al., 2001; Ventura et al., 2007). Phage remnants are also found in these chromosomes, but were not included in the analysis as they have been shown to form a separate subgroup (Ventura et al., 2007).

\section{FUNCTIONAL GENOME DISTRIBUTION OF 26 Lactococcus lactis P335 PHAGES}

Publicly available phage genomes were downloaded in Genbank format from the NCBI genome database. Similarly, publicly available Lactococcus lactis genomes were downloaded in Genbank format, and integrated prophage genomes identified. All phage genomes were then automatically annotated using GAMOLA (Altermann and Klaenhammer, 2003). Predicted ORFeomes of all genomes were subjected to a functional genome distribution analysis (Altermann, 2012) and the resulting distance matrix was imported into MEGA5 (Tamura et al., 2011). The functional distribution was visualized using the UPGMA method (Sneath and Sokal, 1962).

\section{RESULTS}

\section{Lactococcus lactis subsp. cremoris KW2 GENOME SEQUENCE}

The genome of $L$. lactis subsp. cremoris KW2 consists of a $2,427,048$ bp circular chromosome, with a $\mathrm{G}+\mathrm{C}$ content of $36.65 \%$. KW2 has 61 tRNA genes and 2278 coding sequences (CDS) were predicted. The chromosomal gene content of KW2 is highly similar to L. lactis subsp. cremoris dairy starter strains, but KW2 has no plasmids, and the chromosome has no transposases and few pseudogenes. The genome sequence of $L$. lactis subsp. cremoris KW2 has been deposited in the GenBank database under the accession number CP004884.

\section{PROPHAGE $\phi K W 2$ GENOME ORGANIZATION}

The KW2 chromosome contains an integrated $41 \mathrm{~kb}$ prophage genome ( $\Phi \mathrm{KW} 2, \mathrm{kw} 2 \_1785$ to _ 1841). The consolidated gene 
Table 1 | Genomes from lytic and induced P335 species phages, and from P335 prophages located in chromosomes of $L$. lactis strains.

\begin{tabular}{|c|c|c|c|c|c|}
\hline Phage & Status & Host $^{1}$ & Size (kb) & Host origin & Accession no. ${ }^{2}$ \\
\hline 4268 & Lytic & L. lactis subsp. lactis DPC4268 & 37 & Dairy starter & NC_004746 \\
\hline Ф31 (fragment) & Lytic & L. lactis subsp. lactis NCK203 & & Dairy starter & AJ292531 \\
\hline TP901-1 & Temperate/Induced & L. lactis subsp. cremoris 901-1 & 38 & Dairy starter & NC_002747 \\
\hline BK5-T & Temperate/Induced & L. lactis subsp. cremoris BK5 & 40 & Dairy starter & NC_002796 \\
\hline ФடC3 & Temperate/Induced & L. lactis subsp. cremoris IMN-C3 & 32 & Dairy starter & NC_005822 \\
\hline Фsmq86 & Temperate/Induced & L. lactis subsp. cremoris SMQ-86 & 34 & Dairy starter & D0394810 \\
\hline blL285 & Prophage & L. lactis subsp. lactis IL1403 & 36 & Dairy starter & AF323668 \\
\hline bIL286 & Prophage & L. lactis subsp. lactis IL1403 & 42 & & AF323669 \\
\hline t712 & Prophage & L. lactis subsp. cremoris MG1363 & 42 & Dairy starter & NC_009004 \\
\hline MG-3 & Prophage & L. lactis subsp. cremoris MG1363 & 44 & & \\
\hline A76-1 & Prophage & L. lactis subsp. cremoris A76 & 36 & Dairy starter & NC_017492 \\
\hline A76-2 & Prophage & L. lactis subsp. cremoris A76 & 38 & & \\
\hline pp1 & Prophage & L. lactis subsp. lactis KF147 & 35 & Bean sprouts & NC_013656 \\
\hline pp2 & Prophage & L. lactis subsp. lactis KF147 & 54 & & \\
\hline pi1 & Prophage & L. lactis subsp. lactis CV56 & 35 & Human vagina & NC_017486 \\
\hline pi2 & Prophage & L. lactis subsp. lactis CV56 & 37 & & \\
\hline pi3 & Prophage & L. lactis subsp. lactis CV56 & 34 & & \\
\hline ps3 & Prophage & L. lactis subsp. lactis $I \mathrm{O}-1$ & 36 & Kitchen drain & AP012281 \\
\hline
\end{tabular}

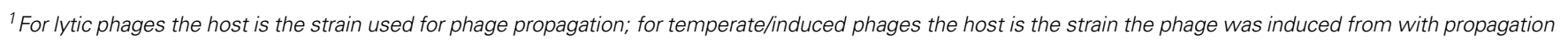

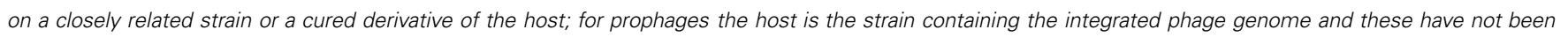
propagated.

${ }^{2}$ Accession numbers are for the phage genome where that is separately available, or for the bacterial genome containing the integrated prophage.

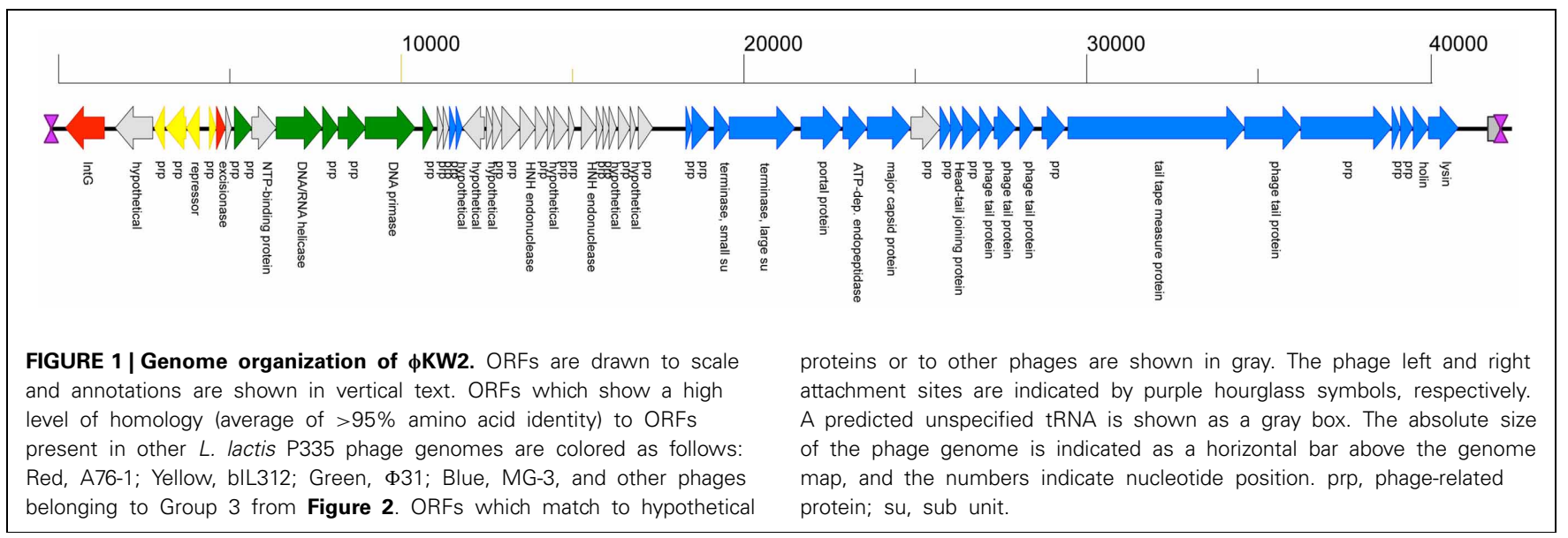

model (Figure 1) shows that $\Phi$ KW2 harbors 57 ORFs, for 22 of which a predicted function could be assigned. A further 28 ORFs could be linked to phage-related homologs without a described function. All ORFs are on the same strand except for a single hypothetical protein (kw2_1822) and the
ORFs involved in establishment and maintenance of lysogeny. The phage ORFs are flanked by 22 -bp sequences indicative of attL and attR sites. A full list of the predicted proteins that are encoded by the $\Phi K W 2$ genome is shown in Table 2. 
Table 2 | Predicted proteins encoded by the prophage $\phi K W 2$.

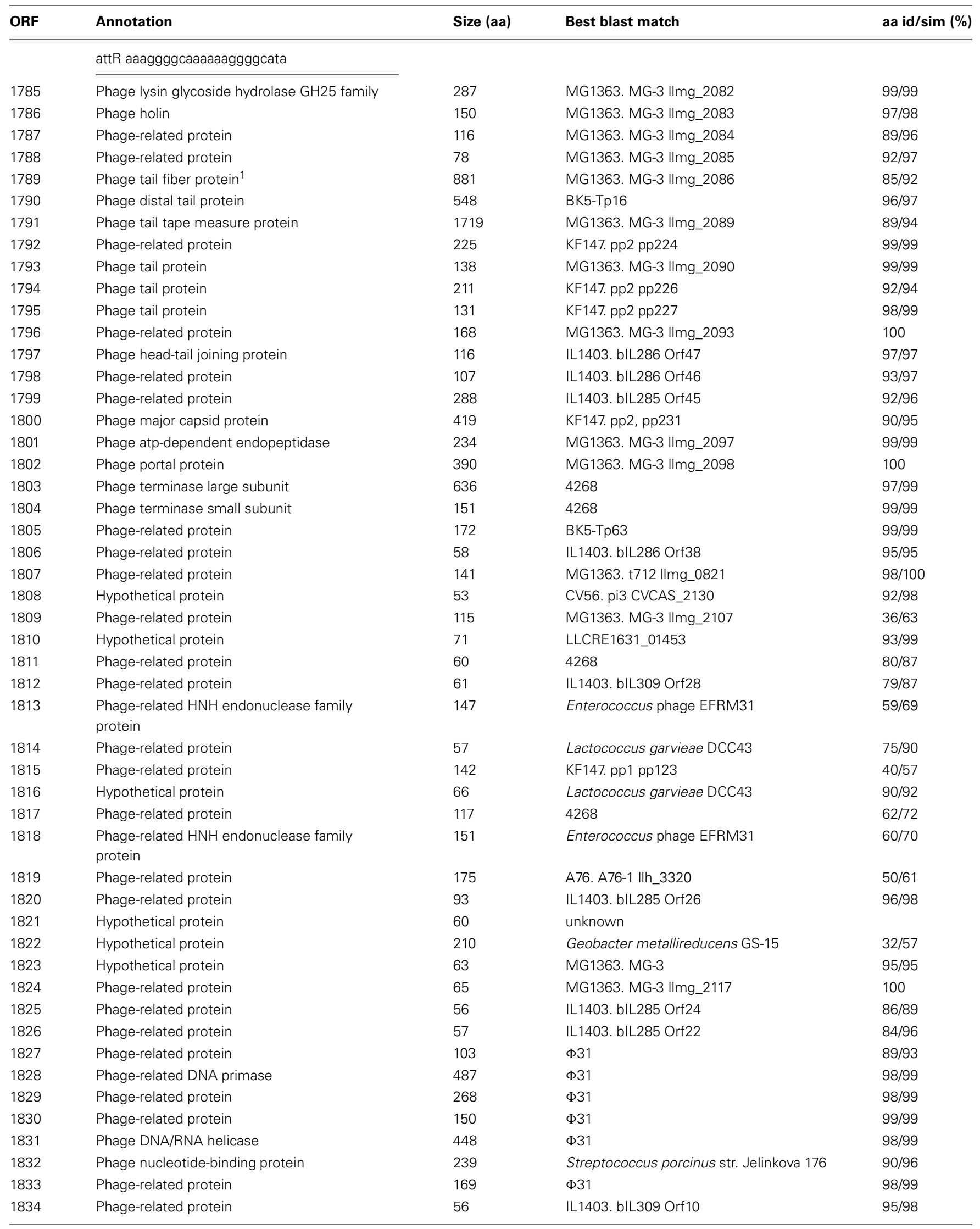


Table 2 | Continued

\begin{tabular}{lllll}
\hline ORF & Annotation & Size (aa) & Best blast match & aa id/sim (\%) \\
\hline 1835 & Excisionase & 86 & A76. A76-1 Ilh_3245 & $98 / 100$ \\
1836 & Phage-related protein & 63 & IL1403. bIL312 Orf6 & $98 / 100$ \\
1837 & Phage repressor & 122 & IL1403. bIL312 Orf5 & $90 / 96$ \\
1838 & Phage-related protein & 195 & IL1403. bIL312 Orf4 & $90 / 95$ \\
1839 & Phage-related protein & 98 & IL1403. bIL312 Orf3 & $99 / 100$ \\
1840 & Hypothetical protein & 364 & Streptococcus oralis SK304 \\
1841 & Phage integrase & 379 & A76. A76-1 Ilh_3210 & $59 / 80$ \\
& attL aaaggggcactaaaggggcata & & & $99 / 99$ \\
\end{tabular}

${ }^{1}$ This is much smaller than the corresponding protein predicted from MG-3 (881 vs. 1617 aa).

\section{COMPARISON OF P335 PHAGE GENOMES}

Functional genome distribution was used to compare the genomes of the phages belonging to the P335 species. The results of this analysis are shown in Figure 2. The 26 phage genomes fall into three broad groups which show a close resemblance to those previously described by others (Trotter et al., 2006; Ventura et al., 2007; Samson and Moineau, 2010). Recently two lytic phages isolated in North America have been sequenced and assigned to a fourth P335 phage group (Mahoney et al., 2013b). The region of the genome devoted to morphogenesis genes is the most conserved (Labrie et al., 2008). From current sequence data the only gene that is conserved among most phages of the P335 species is that for a dUTPase (Labrie and Moineau, 2002). The phage dUTPase is highly conserved at nucleotide and amino acid levels, but differs significantly from the chromosomal dut gene. A phage-like dUTPase is found in each prophage from the dairy L. lactis subsp. cremoris strains but is not part of the $\Phi \mathrm{KW} 2$ genome, suggesting that its acquisition may be associated with adaptation to the dairy environment. The role of the phage dUTPase is not known, but it is hypothesized that dUTPases are involved in controlling various cellular processes (Penadés et al., 2013).

\section{CHROMOSOMAL INTEGRATION}

Analysis of the sequenced L. lactis genomes shows that prophage integration is not random but occurs at a limited number of specific sites on the host chromosome. Currently seven different sites have been identified (Figure 3 ) and each is associated with a highly conserved integrase. The most common location for phage integration is site 4 between the rex and radC genes. There is no relationship between the three groups of phages belonging to the P335 species and the integrase that is present (Figure 2).

\section{HOST SPECIFICITY AND PHAGE RECEPTORS}

Phage infection requires the recognition of receptors on the bacterial cell surface by receptor-binding proteins (RBPs) that are part of the phage tail structure. The RBP from TP901-1 has been characterized and forms part of a complex baseplate structure (Spinelli et al., 2006; Bebeacua et al., 2010, 2013). TP901-1 and the closely related Tuc2009 have similar structural tail proteins, but different host ranges and RBPs (Vegge et al., 2006), and based on their genome sequences other phages of the P335 species are also predicted to have different RBPs. The RBPs are known to bind to carbohydrate cell surface receptors but the exact nature

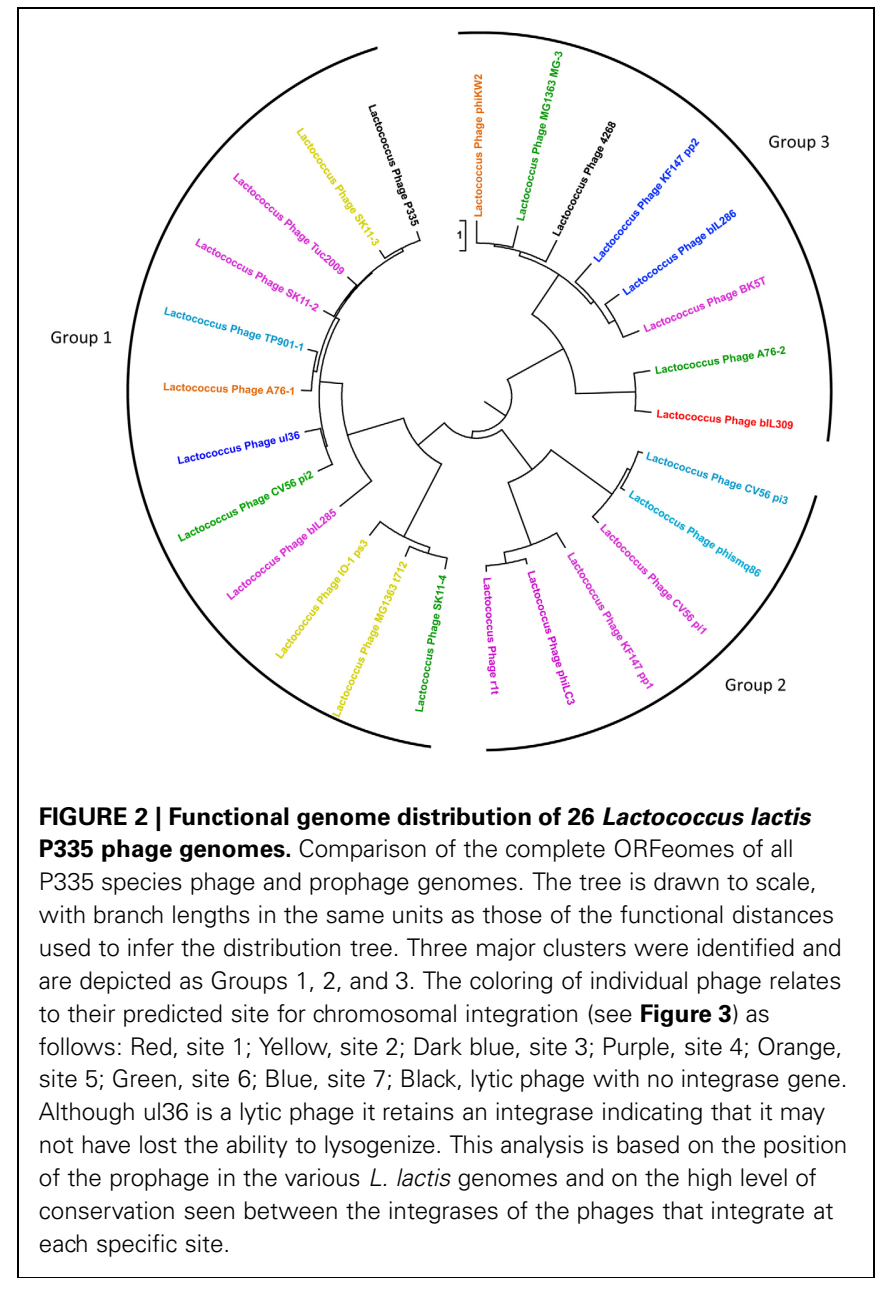

of these remains unknown. However, analysis of the genome of L. lactis subsp. cremoris KW2 suggests that there are possibly four different cell wall polysaccharides (CWP) synthesized by the cell.

L. lactis strains all contain a cluster of $>20$ genes (kw2 0186-_0208) which together determine the biosynthesis of a CWP that forms a pellicle on the cell surface, and is believed to have a role as a bacteriophage receptor for 936 phages (Mahoney et al., 2013a). Genes encoding the biosynthesis and transfer of rhamnose are located at one end of this gene cluster and appear to be 


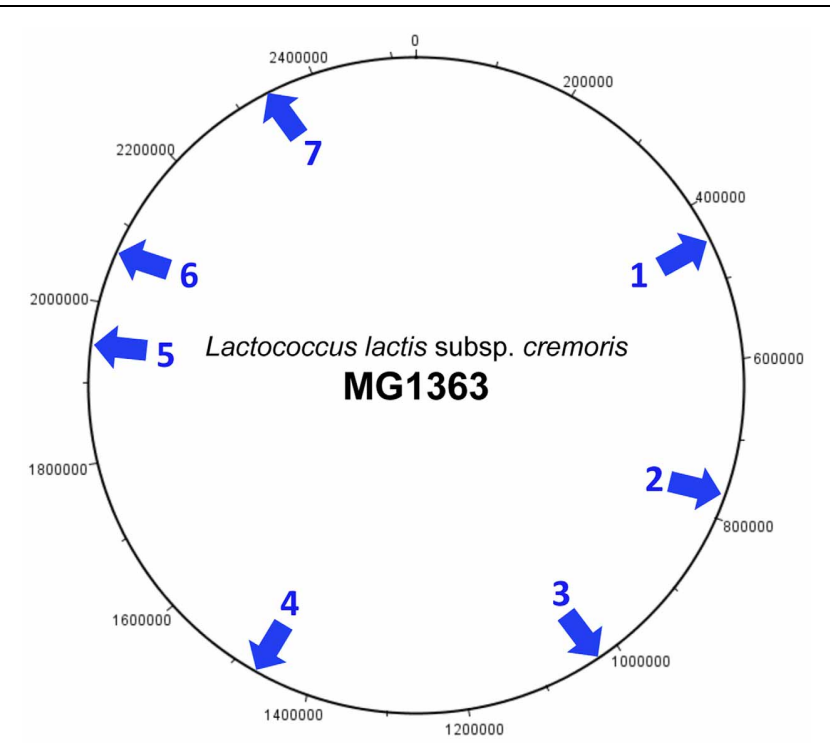

FIGURE 3 | Integration sites of P335 species prophages on the L. lactis subsp. cremoris chromosome. The chromosome of MG1363 is used as a reference. MG1363 is described as a phage- and plasmid-cured derivative of NCDO712, and the genome of the parent strain contains an additional prophage predicted to be integrated at site 7 (Le Bourgeois et al., 2000). The integration sites are located as follows: (1) Adjacent to the tRNA-Arg gene located between IImg_0461 (lytR) and IImg_0462 (truA). (2) Between IImg_0789 (rbsB) and IImg_0856. Location of phage t712. (3) Between IImg_1069 and IImg_1079. (4) Between IImg_1514 (rex) and IImg_1515 (radC). (5) Between Ilmg_1968 and IImg_1969 (sufB). This site is not present in subsp. lactis strains. (6) Between IImg_2081 (sunL) and IImg_2143. Location of phage MG-3. (7) Between IImg_2406 (comGC) and IImg_2407 (comGB).

strongly conserved, but the remainder of the genes vary between the different strains. This variability makes this CWP a suitable candidate as a receptor for phages of the P335 species. A second cluster of potential CWP biosynthesis genes is present in KW2 (kw2_2123-_2131), but some of these are pseudogenes in the L. lactis subsp. cremoris dairy strains, and so this CWP seems an unlikely candidate as a phage receptor as it is probably not produced in all strains.

It is reported that the most likely receptors are believed to be glycerol- or phosphoglycerol-containing wall teichoic acids (WTA) or lipoteichoic acids (LTAs), as their likely variable structures could determine strain specificity (Spinelli et al., 2006). Despite this, little is known about teichoic acid production by L. lactis. Structures have been determined for the LTA and extracellular (wall) teichoic acid components of L. lactis G121 (Fischer et al., 2011, 2012). This strain was isolated from a cowshed and has been shown to have allergy-protective properties, but the teichoic acids are likely to be different to those from the L. lactis subsp. cremoris dairy starter strains used in most phage studies.

Analysis of L. lactis genomes shows that genes for the biosynthesis of WTA occur as a large cluster in the plant L. lactis strain KF147 (Siezen et al., 2011) and also in KW2 (kw2_0901 to_0922). The genes at either end of the cluster which encode the assembly and export functions are conserved but the remaining genes, presumed to determine the sugar composition, differ. The situation is drastically different with the L. lactis subsp. cremoris dairy starter strains. In MG1363 these central genes have been replaced by transposases while in SK11, A76, and UC509.9 only the genes at the ends of the cluster remain. It may be concluded that these dairy strains no longer produce WTA, and it is unlikely to be the phage receptor. How this loss of WTA contributes to the phage resistance phenotype of dairy strains remains to be determined.

Genes encoding the biosynthesis of LTA have been determined for some Gram positive bacteria (Reichmann and Gründling, 2011) but have not been characterized in L. lactis. However, a lipoteichoic acid synthase (LtaS), and two glycolipid biosynthesis glycosyltransferases (LafA and LafB) have been identified in the A76 genome and these are conserved in the other L. lactis subsp. cremoris strains including KW2 (kw2_0755, and kw2_2197-_2198). Other genes involved in biosynthesis of the carbohydrate moieties of the LTA remain to be identified. These strains also have the dltA-D operon which mediates the Dalanylation of LTA and contributes to the cell surface properties (Giaouris et al., 2008). Consequently LTA is a candidate for a cell surface receptor likely to be recognized by phages of the P335 species, although it appears to lack the necessary strain variability. Consequently accurate identification of the host receptor awaits further study.

\section{PHAGES OF THE P335 SPECIES AS AGENTS OF GENE TRANSFER AND CHROMOSOMAL REARRANGEMENT}

Transduction of genetic information by temperate phages has been described for lactococci and used to study plasmidassociated lactose and proteinase phenotypes in NCDO712 and related strains (Gasson, 1990). Recently, Wegmann et al. (2012) used plasmid transduction by the $\Phi T P 712$ (t712) phage in their analysis of the pLP712 plasmid from NCDO712, but otherwise transduction has been seldom used with L. lactis. There is no information available on transduction by temperate phages from other lactococcal strains, and consequently their role in horizontal gene transfer is not known. Lysogenic conversion can be viewed as a type of specialized transduction, and in the Gram positive pathogens Staphylococcus aureus and Streptococcus pyogenes, lysogenic conversion genes involved in virulence are found located distal to the phage lysin. Examination of the prophages from the dairy L. lactis subsp. cremoris strains suggests that lysogenic conversion is not common. However, the t712 prophage found in MG1363 does have an abortive infection gene located between the lysin and attR site (Ventura et al., 2007).

Analysis of the L. lactis subsp. cremoris genomes shows that P335 species prophages can be involved in mediating significant changes to chromosomal architecture. In L. lactis subsp. cremoris A76 the prophage integration sites 1 and 6 are found at the ends of a chromosomal rearrangement. The chromosome of strain A76 has truncated integrase, repressor and phage lysin genes adjacent to the lyt R gene (llh_2555, site 1). This region also contains several transposases and then joins to the ribosomal RNA small subunit methyltransferase B gene (sunL, llh_2615, site 6). Phage A76-2 is located at the other end of the chromosomal 
rearrangement. The phage integrase (llh_10885) is adjacent to the A76 homolog of llmg_2143 (llh_10890, site 6), while the lysin gene (llh_10615) is separated from truA (llh_10580, site 1) by a transposase and other hypothetical proteins. A similar situation possibly applies with other $L$. lactis subsp. cremoris strains HP and FG2 (Kelly et al., 2010) that show similar chromosomal rearrangements to strain A76.

\section{DISCUSSION}

Phages that attack Lactococcus lactis dairy starter cultures remain the largest single cause of industrial milk fermentation problems and result in significant economic losses. While most problems result from infection by virulent 936 and c2 species phages, (Madera et al., 2004), phages of the P335 species are also of interest as they likely originate from the starter cultures themselves. However, it is not clear what proportion of significant problems result from the phages of the P335 species. While some P335 phages have adopted a lytic lifestyle, it is possible that this is a relatively rare event, as the lytic $\mathrm{P} 335$ phages have a narrow host range (Moineau et al., 1996), and it has proved difficult to find propagation hosts for temperate phages that have been induced from L. lactis dairy strains. Nevertheless, Labrie and Moineau (2007) have clearly shown how a lytic P335 phage can exchange functional modules with an integrated prophage to rapidly generate novel combinations with altered properties.

Most studies of phages belonging to the P335 species have been in the context of their association with dairy strains of L. lactis subsp. cremoris, and here we report the genome sequence of L. lactis subsp. cremoris KW2 that was isolated from fermented corn. The most notable feature of the KW2 chromosome is that it does not show the high numbers of transposases and pseudogenes characteristic of L. lactis subsp. cremoris dairy starters, but it does contain a single integrated prophage ( $\Phi$ KW2). Phage evolution occurs by the rearrangement of functional modules, and it seems clear that phages are able to mix-and-match these modules to produce a variety of different combinations. $\Phi \mathrm{KW} 2$ serves as an example of this as its mosaic structure appears little different from the prophages found in dairy starters, and its various functional modules show very high homology to known dairy phages. The integrase and excisionase (which both match to the A76-1 prophage), the early gene control module including the phage repressors (matches to the P335 phage remnant bIL312 found in the IL1403 genome), and the DNA replication module (matches to the replication genes from the lytic phage $\Phi 31$ ) are located at

\section{REFERENCES}

Ainsworth, S., Zomer, A., de Jager, V., Bottacini, F., van Hijum, S. A. F. T., Mahoney, J., et al. (2013). Complete genome of Lactococcus lactis subsp. cremoris UC509.9, host for a model lactococcal P335 bacteriophage. Genome Announc. 1, e00119-e00112. doi: 10.1128/ genomeA.00119-12

Altermann, E. (2012). Tracing lifestyle adaptation in prokaryotic genomes. Front. Microbiol.
3:48. doi: 10.3389/fmicb.2012. 00048

Altermann, E., and Klaenhammer, T. (2003). GAMOLA: a new local solution for sequence annotation and analyzing draft and finished prokaryotic genomes. Omics 7, 161-169. doi: 10.1089/ 153623103322246557

Bebeacua, C., Bron, P., Lai, L., Vegge, C. S., Brøndsted, L., Spinelli, S., et al. (2010). Structure and molecular assignment of lactococcal

one end of the genome. The proteins predicted to be encoded by the central region of the genome show only weak homology mainly to proteins from various phage genomes, and this is typical of other phages from the P335 species. The remaining three modules for DNA packaging, phage structural components (including head and tail morphogenesis and host specificity), and cell lysis are found at the other end of the genome and almost all of the genes in this region show high homology to phage MG3 from the MG1363 genome and to other phages that make up Group 3 in Figure 2.

The ability of phages of the P335 species to shuffle their various modules means that no $L$. lactis subsp. cremoris strains can be said to be truely phage-unrelated. The integrases are a good example as they enable phages to insert at a limited number of specific sites and yet can be partnered with a diversity of different modules as shown in Figure 2. Using conserved primer sequences from four P335 phages that insert at integration site 4 (Tuc2009, r1t, BK5-T, and ФLC3), O'Sullivan et al. (2000) showed that 19 of 31 cheese-making lactococcal strains gave a product of the expected size indicating the presence of a specific integrase gene, and by implication a prophage inserted at this location. The lytic behavior of these strains could be correlated with the presence of this prophage sequence.

It can be concluded from this that P335 species prophages are an integral part of the Lactococcus lactis genome, and their interaction can take several different forms. The prophage may be induced from the genome and in some cases become a lytic phage that is unable to relysogenize. Prophages may also mediate chromosomal rearrangement as appears to be the case for L. lactis subsp. cremoris A76, or acquire lysogenic conversion genes that modify bacterial properties. In the case of dairy starter cultures prophages may also influence important industrial properties of the strains such as phage resistance and autolysis. Overall it is difficult to quantify the effect of prophage genomes, and it appears most likely that they have co-evolved together with the bacterial genome. The observation that many of the prophages in dairy strains of L. lactis subsp. cremoris contain transposases suggests that prophage genomes are exposed to the same selection as the host genome, and that prophages may have had only a minor role in the adaptation of Lactococcus lactis strains to the dairy environment.

\section{ACKNOWLEDGMENTS}

This work was supported by the AgResearch Curiosity Fund.

phage TP901-1 baseplate. J. Biol. Chem. 285, 39079-39086. doi: 10.1074/jbc.M110.175646

Bebeacua, C., Lai, L., Vegge, C. S., Brøndsted, L., van Heel, M., Veesler, D., et al. (2013). Visualizing a complete Siphoviridae member by single-particle electron microscopy: the structure of lactococcal phage TP901-901. J. Virol. 87, 1061-1068. doi: 10.1128/JVI.02836-12

Blatny, J. M., Godager, L., Lunde, M., and Nes, I. F. (2004). Complete genome sequence of the Lactococcus lactis temperate phage ФLC3: comparative analysis of $\Phi L C 3$ and its relatives in lactococci and streptococci. Virology 318, 231-244. doi: 10.1016/j.virol.2003. 09.019

Bolotin, A., Quinquis, B., Ehrlich, D. S., and Sorokin, A. (2012). Complete genome sequence of Lactococcus lactis subsp. cremoris A76. J. Bacteriol. 194, 1241-1242. doi: 10.1128/JB.06629-11 
Bolotin, A., Wincker, P., Mauger, S., Jaillon, O., Malarme, K., Weissenbach, J., et al. (2001). The complete genome sequence of the lactic acid bacterium Lactococcus lactis ssp. lactis IL1403. Genome Res. 11, 731-753. doi: 10.1101/gr.GR-1697R

Braun, V., Hertwig, S., Neve, H., Geis, A., and Teuber, M. (1989). Taxonomic differentiation of bacteriophages of Lactococcus lactis by electron microscopy, DNA-DNA hybridization, and protein profiles. J. Gen. Microbiol. 135, 2551-2560.

Brøndsted, L., Østergaard, S., Pedersen, M., Hammer, K., and Vogensen, F. K. (2001). Analysis of the complete DNA sequence of the temperate bacteriophage TP901-1: evolution, structure, and genome organization of lactococcal bacteriophages. Virology 283, 93-109. doi: 10.1006/viro.2001.0871

Chopin, A., Bolotin, A., Sorokin, A., Ehrlich, S. D., and Chopin, M.-C. (2001). Analysis of six prophages in Lactococcus lactis IL1403: different genetic structure of temperate and virulent phage populations. Nucleic Acids Res. 29, 644-651. doi: 10.1093/nar/29.3.644

Delcher, A., Harmon, D., Kasif, S., White, O., and Salzberg, S. (1999). Improved microbial gene identification with GLIMMER. Nucleic Acids Res. 27, 4636-4641. doi: $10.1093 / \mathrm{nar} / 27.23 .4636$

Desiere, F., Mahanivong, C., Hillier, A. J., Chandry, P. S., Davidson, B. E., and Brüssow, H. (2001). Comparative genomics of lactococcal phages: insight from the complete genome sequence of Lactococcus lactis phage BK5T. Virology 283, 240-252. doi: 10.1006/viro.2001.0857

Deveau, H., Labrie, S. J., Chopin, M. C., and Moineau, S. (2006). Biodiversity and classification of lactococcal phages. Appl. Environ. Microbiol. 72, 4338-4346. doi: 10.1128/AEM.02517-05

Fischer, K., Stein, K., Ulmer, A. J., Lindner, B., Heine, H., and Holst, O. (2011). Cytokine-inducing lipoteichoic acids of the allergy-protective bacterium Lactococcus lactis G121 do not activate via Toll-like receptor 2. Glycobiology 21, 1588-1595. doi: 10.1093/glycob/cwr071

Fischer, K., Vinogradov, E., Lindner, B., Heine, H., and Holst, O. (2012). The structure of the extracellular teichoic acids from the allergy-protective bacterium Lactococcus lactis G121. Biol. Chem. 393, 749-755. doi: 10.1515/hsz-2012-0142
Gao, Y., Lu, Y., Teng, K.-L., Chen, M.L., Zheng, H.-J., Zhu, Y.-Q., et al. (2011). Complete genome sequence of Lactococcus lactis subsp. lactis CV56, a probiotic strain isolated from the vagina of healthy women. J. Bacteriol. 193, 2886-2887. doi: 10.1128/JB.00358-11

Gasson, M. J. (1990). In vivo genetic systems in lactic acid bacteria. FEMS Microbiol. Rev. 87, 43-60. doi: $\quad 10.1111 /$ j.1574-6968.1990. tb04878.x

Giaouris, E., Briandet, R., Meyrand, M., Courtin, P., and Chapot-Chartier, M.-P. (2008). Variations in the degree of D-alanylation of teichoic acids in Lactococcus lactis alter resistance to cationic antimicrobials but have no effect on bacterial surface hydrophobicity and charge. Appl. Environ. Microbiol. 74, 4764-4767. doi: 10.1128/AEM. 00078-08

Haft, D. H., Selengut, J. D., Richter, R. A., Harkins, D., Basu, M. K., and Beck, E. (2013). TIGRFAMs and Genome properties in 2013. Nucleic Acids Res. 41, D387-D395. doi: 10.1093/nar/gks1234

Huggins, A. R., and Sandine, W. E. (1977). Incidence and properties of temperate bacteriophages induced from lactic streptococci. Appl. Environ. Microbiol. 33, 184-191.

Jarvis, A. W., Fitzgerald, G. F., Mata, M., Mercenier, A., Neve, H., Powell, I. B., et al. (1991). Species and type phages of lactococcal bacteriophages. Intervirology 32, 2-9.

Kato, H., Shiwa, Y., Oshima, K., Machii, M., Araya-Kojima, T., Zendo, T., et al. (2012). Complete genome sequence of Lactococcus lactis IO-1, a lactic acid bacterium that utilizes xylose and produces high levels of L-lactic acid. J. Bacteriol. 194, 2102-2103. doi: 10.1128/JB.00074-12

Kelly, W. J., Ward, L. J. H., and Leahy, S. C. (2010). Chromosomal diversity in Lactococcus lactis and the origin of dairy starter cultures. Genome Biol. Evol. 2, 729-744.

Labrie, S., and Moineau, S. (2002). Complete genomic sequence of bacteriophage ul36: demonstration of phage heterogeneity within the P335 quasi-species of lactococcal phages. Virology 296, 308-320. doi: 10.1006/viro.2002.1401

Labrie, S. J., Josephsen, J., Neve, H., Vogensen, F. K., and Moineau, S. (2008). Morphology, genome sequence, and structural proteome of type phage P335 from Lactococcus lactis. Appl. Environ. Microbiol. 74, 4636-4644. doi: 10.1128/AEM.00118-08
Labrie, S. J., and Moineau, S. (2007). Abortive infection mechanisms and prophage sequences significantly influence the genetic makeup of emerging lytic lactococcal phages. J. Bacteriol. 189, 1482-1487. doi: 10.1128/JB.01111-06

Lawrence, R. C., Heap, H. A., Limsowtin, G., and Jarvis, A. W. (1978). Cheddar cheese starters: current knowledge and practices of phage characteristics and strain selection. J. Dairy Sci. 61, 1181-1191. doi: 10.3168/jds.S00220302(78)83703-5

Le Bourgeois, P., Daveran-Mingot, M.-L., and Ritzenthaler, P. (2000). Genome plasticity among related Lactococcus strains: identification of genetic events associated with macrorestriction polymorphisms. J. Bacteriol. 182, 2481-2491. doi: 10.1128/JB.182.9.2481-2491.2000

Madera, C., Monjardín, C., and Suárez, J. E. (2004). Milk contamination and resistance to processing conditions determine the fate of Lactococcus lactis bacteriophages in dairies. Appl. Environ. Microbiol. 70, 7365-7371. doi: $\quad$ 10.1128/AEM.70.12.73657371.2004

Madsen, S. M., Mills, D., Djordjevic, G., Israelsen, H., and Klaenhammer, T. R. (2001). Analysis of the genetic switch and replication region of a P335-type bacteriophage with an obligate lytic lifestyle on Lactococcus lactis. Appl. Environ. Microbiol. 67, 1128-1139. doi 10.1128/AEM.67.3.1128-1139.2001

Mahoney, J., Kot, W., Murphy, J., Ainsworth, S., Neve, H., Hansen, L. H., et al. (2013a). Investigation of the relationship between lactococcal cell wall polysaccharide genotype and 936 phage receptor binding protein phylogeny. Appl. Environ. Microbiol. 79, 4385-4392. doi: 10.1128/AEM.00653-13

Mahoney, J., Martel, B., Tremblay, D. M., Neve, H., Heller, K. J., Moineau, S., et al. (2013b). Identification of a new P335 subgroup through molecular analysis of lactococcal phages Q33 and BM13. Appl. Environ. Microbiol. 79, 4401-4409. doi: 10.1128/AEM.00832-13

Makarova, K., Slesarev, A., Wolf, Y., Sorokin, A., Mirkin, B., Koonin, E., et al. (2006). Comparative genomics of the lactic acid bacteria. Proc. Natl. Acad. Sci. U.S.A. 103, 15611-15616. doi: 10.1073/pnas.0607117103

Moineau, S., Borkaev, M., Holler, B. J., Walker, S. A., Kondo, J. K., Vedamuthu, E. R., et al. (1996). Isolation and characterization of lactococcal bacteriophages from cultured buttermilk plants in the United States. J. Dairy Sci. 79, 2104-2111. doi: 10.3168/jds.S00220302(96)76584-0

O'Sullivan, D., Ross, R. P., Fitzgerald, G. F., and Coffey, A. (2000). Investigation of the relationship between lysogeny and lysis of Lactococcus lactis in cheese using prophage-targeted PCR. Appl. Environ. Microbiol. 66, 2192-2198. doi: 10.1128/AEM.66.5.2192-2198. 2000

Penadés, J. R., Donderis, J., GarcíaCaballer, M., Tormo-Más, M. Á., and Marina, A. (2013). dUTPases, the unexplored family of signalling molecules. Curr. Opin. Microbiol. 16, 163-170. doi: 10.1016/j.mib.2013.02.005

Punta, M., Coggill, P. C., Eberhardt, R. Y., Mistry, J., Tate, J., Boursnell, C., et al. (2012). The Pfam protein families database. Nucleic Acids Res. 40, D290-D301. doi: 10.1093/nar/gkr1065

Rademaker, J. L. W., Herbert, H., Starrenburg, M. J. C., Naser, S. M., Gevers, D., Kelly, W. J., et al. (2007). Diversity analysis of dairy and nondairy Lactococcus lactis isolates, using a novel multilocus sequence analysis scheme and (GTG)5-PCR fingerprinting. Appl. Environ. Microbiol. 73, 7128-7137. doi: 10.1128/AEM.01017-07

Reichmann, N. T., and Gründling, A. (2011). Location, synthesis and function of glycolipids and polyglycerolphosphate lipoteichoic acid in Gram-positive bacteria of the phylum Firmicutes. FEMS Microbiol. Lett. 319, 97-105. doi: 10.1111/j.1574-6968.2011.02260.x

Rutherford, K., Parkhill, J., Crook, J., Horsnell, T., Rice, P., Ranjandream, M.-A., et al. (2000). Artemis: sequence visualization and annotation. Bioinformatics 16, 944-945. doi: 10.1093/bioinformatics/16.10.944

Samson, J. E., and Moineau, S. (2010). Characterization of Lactococcus lactis phage 949 and comparison with other lactococcal phages. Appl. Environ. Microbiol. 76, 6843-6852. doi: 10.1128/AEM.00796-10

Santer, M. (2010). Joseph Lister: first use of a bacterium as a 'model organism' to illustrate the cause of infectious disease of humans. Notes Rec. R. Soc. Lond. 64, 59-65. doi: 10.1098/rsnr.2009.0029

Siezen, R. J., Bayjanov, J., Renckens, B., Wels, M., van Hijum, S. A. F. T., Molenaar, D., et al. (2010). Complete genome sequence of Lactococcus lactis subsp. lactis KF147, a 
plant-associated lactic acid bacterium. J. Bacteriol. 192, 2649-2650. doi: 10.1128/JB.00276-10

Siezen, R. J., Bayjanov, J. R., Felis, G. E., van der Sijde, M. R., Starrenburg, M., Molenaar, D., et al. (2011). Genome-scale diversity and niche adaptation analysis of Lactococcus lactis by comparative genome hybridization using multi-strain arrays. Microb. Biotechnol. 4, 383-402. doi: 10.1111/j.1751-7915.2011.00247.x

Sneath, P. H., and Sokal, R. R. (1962). Numerical taxonomy. Nature 193, 855-860. doi: 10.1038/193855a0

Spinelli, S., Campanacci, V., Blangy, S., Moineau, S., Tegoni, M., and Cambillau, C. (2006). Modular structure of the receptor binding proteins of Lactococcus lactis phages. The RBP structure of the temperate phage TP901-901. J. Biol. Chem. 281, 14256-14262. doi: 10.1074/jbc.M600666200

Staden, R., Beal, K. F., and Bonfield, J. K. (2000). The Staden package, 1998. Methods Mol. Biol. 132, 115-130.

Tamura, K., Peterson, D., Peterson, N., Stecher, G., Nei, M., and Kumar, S. (2011). MEGA5: molecular evolutionary genetics analysis using maximum likelihood, evolutionary distance, and maximum parsimony methods. Mol. Biol. Evol. 28, 2731-2739. doi: $10.1093 / \mathrm{molbev} / \mathrm{msr} 121$
Tatusov, R., Galperin, M., Natale, D., and Koonin, E. (2000). The COG database: a tool for genome-scale analysis of protein functions and evolution. Nucleic Acids Res. 28, 33-36. doi: 10.1093/nar/28.1.33

Terzaghi, B. E., and Sandine, W. E. (1981). Bacteriophage production following exposure of lactic streptococci to ultraviolet radiation. J. Gen. Microbiol. 122, 305-311.

Trotter, M., McAuliffe, O., Callanan, M., Edwards, R., Fitzgerald, G. F., Coffey, A., et al. (2006). Genome analysis of the obligately lytic bacteriophage 4268 of Lactococcus lactis provides insight into its adaptable nature. Gene 366, 189-199. doi: 10.1016/j.gene.2005. 09.022

van Sinderen, D., Karsens, H., Kok, J., Terpstra, P., Ruiters, M. H., Venema, G., et al. (2006). Sequence analysis and molecular characterization of the temperate lactococcal bacteriophage r1t. Mol. Microbiol. 19, 1343-1355. doi: 10.1111/j.13652958.1996.tb02478.x

Vegge, C. S., Vogensen, F. K., McGrath, S., Neve, H., van Sinderen, D., and Brøndsted, L. (2006). Identification of the lower baseplate protein as the antireceptor of the temperate lactococcal bacteriophages TP901-1 and Tuc2009. J. Bacteriol. 188, 55-63. doi: 10.1128/JB.188.1.5563.2006
Ventura, M., Zomer, A., Canchaya, C., O'Connell-Motherway, M., Kuipers, O., Turroni, F., et al. (2007). Comparative analyses of prophage-like elements present in two Lactococcus lactis strains. Appl. Environ. Microbiol. 73, 7771-7780. doi: 10.1128/AEM.01273-07

Wegmann, U., O'Connell-Motherway, M., Zomer, A., Buist, G., Shearman, C., Canchaya, C., et al. (2007). Complete genome sequence of the prototype lactic acid bacterium Lactococcus lactis subsp. cremoris MG1363. J. Bacteriol. 189, 3256-3270. doi: 10.1128/JB. 01768-06

Wegmann, U., Overweg, K., Jeanson, S., Gasson, M., and Shearman, C. (2012). Molecular characterization and structural instability of the industrially important composite metabolic plasmid pLP712. Microbiology 158, 2936-2945. doi: 10.1099/mic.0.062554-0

Whitehead, H. R. (1953). Bacteriophage in cheese manufacture. Bacteriol. Rev. 17, 109-123.

Whitehead, H. R., and Bush, E. J. (1957). Phage-organism relationships among strains of Streptococus cremoris: the selection of strains as cheese starters. J. Dairy Res. 24, 381-386. doi: 10.1017/S0022029900008931

Whitehead, H. R., and Cox, G. A. (1936). Phage phenomena in cultures of lactic streptococci. J. Dairy Res. 7, 55-62. doi: $10.1017 /$ S0022029900001655

Conflict of Interest Statement: The authors declare that the research was conducted in the absence of any commercial or financial relationships that could be construed as a potential conflict of interest.

Received: 07 July 2013; paper pending published: 26 July 2013; accepted: 13 August 2013; published online: 30 August 2013.

Citation: Kelly WJ, Altermann E, Lambie SC and Leahy SC (2013) Interaction between the genomes of Lactococcus lactis and phages of the P335 species. Front. Microbiol. 4:257. doi: 10.3389/ fmicb.2013.00257

This article was submitted to Food Microbiology, a section of the journal Frontiers in Microbiology.

Copyright (c) 2013 Kelly, Altermann, Lambie and Leahy. This is an openaccess article distributed under the terms of the Creative Commons Attribution License (CC BY). The use, distribution or reproduction in other forums is permitted, provided the original author(s) or licensor are credited and that the original publication in this journal is cited, in accordance with accepted academic practice. No use, distribution or reproduction is permitted which does not comply with these terms. 